\title{
Death due to Late Complication of Paranasal Sinus Fracture Following Road Traffic Trauma
}

\author{
Mahendran Kogulshankar ${ }^{1 *} \otimes(D)$, Muditha Vidanapathirana \\ Department of Forensic Medicine, Faculty of Medical Sciences, University of Sri \\ Jayewardenepura, Sri Lanka
}

The nose and maxilla are components of the danger triangle. Due to the special nature of the blood supply to the human nose can lead to cavernous sinus thrombosis, meningitis or brain abscess. Frontal and maxillary sinus infection leads to early and delayed complications. In this case, lack of information had been given to the patient by the clinicians on discharge regarding review examination. An elderly alcoholic was admitted to a tertiary care hospital following road traffic trauma. He had received fractures of right maxillary bone and frontal sinus with frontal lobe brain contusion. CT scan showed fluid levels in the bilateral maxillary sinus. He was treated inward for two weeks and was discharged. He was advised to come for review examination in one week but defaulted and had not also taken antibiotics regularly. Two weeks later, he was re-admitted with spiky fever for three days. On admission, he was drowsy and had neutrophil leukocytosis. He died two days after admission. The autopsy revealed yellow pus and abscesses on the brain surface. Other organs showed septic features. The cause of death was brain abscesses and meningitis following blunt force trauma to head. The brain abscesses and meningitis were complications of sinus fracture following road traffic accident of an alcoholic who had not followed proper medical advice. A multidisciplinary approach and a proper follow up is needed to prevent such deaths due to late complications. We highlight that adequate information should be given to both patient and relatives especially when the patient is an alcoholic to prevent the late complications and death.

Keywords: Frontal and maxillary sinus, Fracture, Brain abscess.

Copyright: @ 2018 with the Medico-legal Journal of Sri Lanka.

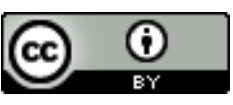

This is an open-access article distributed under the terms of the Creative Commons Attribution 4.0 International License, which permits unrestricted use, distribution and reproduction in any medium provided the original author and source are credited.

Funding: None,

\section{Competing interests: None}

Received: 17 April 2018 Accepted revised version: 01 May 2018 Published: 30 June 2018

*Corresponding author: Kogulshankar M, E-mail: kogul10@gmail.com $ه$, Tel: +94776630230

(D) https://orcid.org/0000-0001-5244-2466

Cite this article as: Kogulshankar M, Vidanapathirana M. Death due to Late Complication of Paranasal Sinus Fracture following road traffic trauma. Medico-Legal Journal of Sri Lanka, 2018;6(1): 35-38.

DOI: http://dx.doi.org/10.4038/mljsl.v6i1.7371 


\section{Introduction}

The sinuses are air-filled cavities inside of the skull bone that have a protective role during trauma. ${ }^{[1]}$ The maxillary sinuses sit below the eyes within the cheek region and seem to play a major role in protecting the eyes during trauma. Approximately $8 \%$ of all facial fractures are usually a result of road traffic accidents..$^{[1,2]}$ Such fractures are predisposed to contamination, sinus infection and obstruction. ${ }^{[3]}$ The overall complication rate following frontal and maxillary sinus infection approaches $10-20 \%$ and includes early and delayed complications. ${ }^{[4]}$ The danger triangle of the face consists of the area from the corners of the mouth to the bridge of the nose, including the nose and maxilla. Due to the special nature of the blood supply to the human nose can lead to cavernous sinus thrombosis, meningitis or brain abscess. ${ }^{[5]}$

The clinician must be aware of the potential for these complications because late recognition of this condition and delays in treatment can increase morbidity and mortality rates. ${ }^{[6]}$ This case discussion is based on a death following a road traffic trauma due to late complications.

\section{Case report}

A 79-year-old pedestrian was admitted to a tertiary care hospital following road traffic trauma with a head injury. At the time of admission, his GCS was 10/15, he was under the influence of alcohol. He had a laceration over right supra-orbital ridge and fractures of right maxillary bone and frontal sinus with a small contusion in the right frontal lobe of the brain. CT scan showed right frontal sinus fracture and fluid levels in bilateral maxillary sinuses. He was treated inward manage with intravenous antibiotics and analgesics for two weeks and was discharged. No surgery was done for brain contusion.

The patient was stable and GCS was $15 / 15$ on discharge. He was advised to come for review examination in one week but he did not come and had also not taken antibiotics regularly. He again started to drink liquor. Two weeks later, he was re-admitted with spiky fever for three days. On admission, he was drowsy and had neutrophil leukocytosis and very high CRP. He died two days after admission.

Autopsy examination revealed a healing laceration over the outer aspect of the right eyebrow. Fractures of right maxillary bone and right frontal sinus were found. Internal examination revealed that the dural membrane was intact. The brain was congested, enlarged, weighing $1500 \mathrm{~g}$. Sulci were narrowed and the gyri were flattened and yellow pus and abscesses were found on the surface and markedly found along the blood vessels (Fig. 01). There were pus and abscesses especially over the cerebellum too (Fig. 02). Histopathology of the brain surface showed discrete lesions with central liquefactive necrosis and purulent centres, and infiltration of polymorphs. Subarachnoid space was filled with purulent exudate and polymorphs.

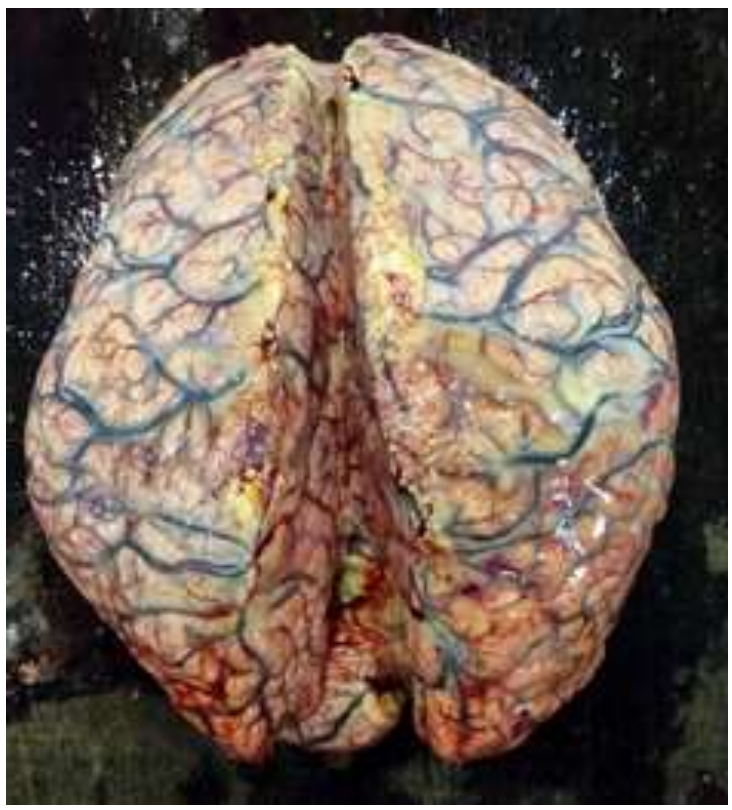

Figure 1: Superior view of the brain shows diffuse pus and abscesses on the surface of the brain.

Other organs showed septic features such as consolidation of lungs and enlarged kidneys. The cause of death was brain abscesses and meningitis following blunt force trauma to head. Relatives alleged that they were not adequately informed regarding the condition or potential complications on discharge. 


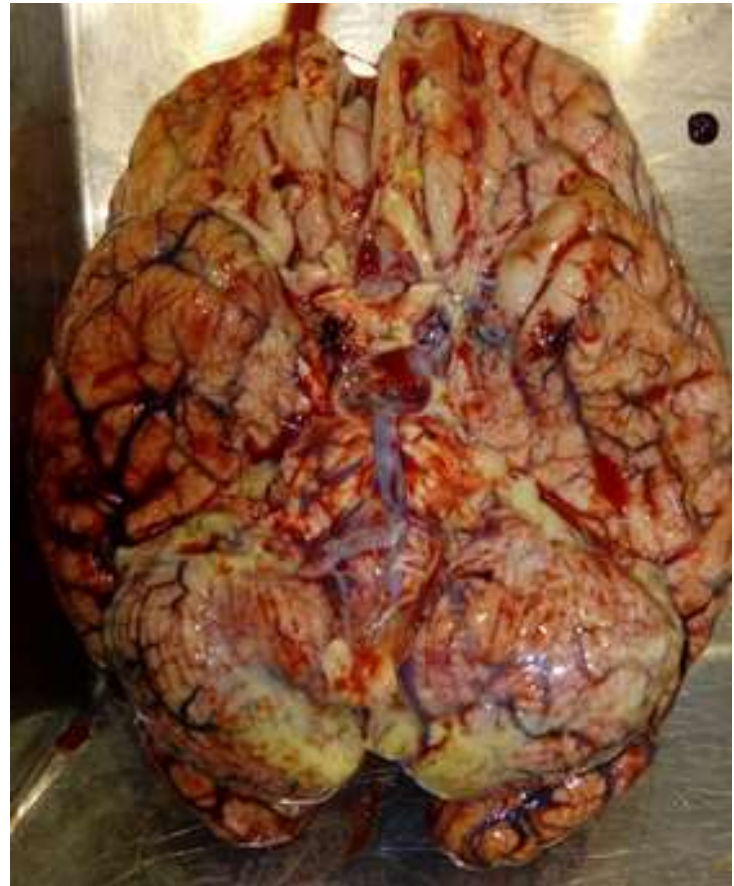

Figure 2: Base of the brain shows pus and abscesses mainly over the cerebellum.

\section{Discussion}

In our case, since the patient was an alcoholic and defaulted on regular treatments and antibiotics, had a high chance of getting infections. Since he was elderly, he might have become more vulnerable to injury because of frailty, ill health, or dependency. ${ }^{[7]}$ Fractures of right frontal sinus and maxillary sinus could be the source of infection which had spread to the brain.

Brain abscesses usually originate from frontal sinusitis, rarely from the ethmoidal system or the maxillary sinus. ${ }^{[8]}$ However, there are different pathways that can lead to the transfer of a maxillary infection to the brain. ${ }^{[8]}$ The venous plexus of the maxillary sinus drains into the deep facial vein that leads into the pterygoid plexus and then into the cavernous sinus. In addition, numerous small veins perforate the osseous roof of the maxillary sinus and enter the orbit joining the superior or inferior ophthalmic vein. They are also connected to the cavernous sinus or the pterygoid plexus. A number of veins perforate the anterior wall of the maxillary sinus communicating with the angular vein that drains into the superior ophthalmic vein and into the cavernous sinus. From the cavernous sinus, the blood arrives at the deep middle cerebral vein that usually communicates through the white substance towards the brain's superficial venous system. ${ }^{[8]}$

The cause of death was brain abscesses and meningitis following blunt force trauma to the head. Since he got admitted to the hospital late, he had developed very high neutrophilic leukocytosis and CRP and the infection had spread to the other organs as well. If he had taken proper medical attention and followed the medical advice, the spread of the infection and the death could have been prevented.

The allegation made by the relatives that they were not adequately informed regarding the condition or potential complications has to be considered seriously. Since he was an alcoholic person, not only the patient but also the relatives could have been provided with proper medical advice regarding his condition and its complications. His alcohol dependency had not been addressed at the hospital such as referral to a psychiatrist or multidisciplinary approach.

\section{Conclusion}

This is the case of brain abscesses and meningitis were late complications of sinus fracture following road traffic accident of an alcoholic who did not follow proper medical advice. Optimum stabilization and proper follow up is needed to prevent such deaths due to late complications. Since he was an alcoholdependent patient, we need to provide special attention and give proper medical advice regarding late complications not only to the patent but also to the relatives. A multidisciplinary approach including caregivers is needed to prevent such deaths in dependent patients.

\section{References}

1. Luce EA. Frontal sinus fractures: Guidelines to management. PlastReconstr Surg. 1987;80(4):500-10. PMID: 3659160

2. Gerbino G, Roccia F, Benech A, Caldarelli C. Analysis of 158 frontal sinus fractures: Current surgical management and complications. J Craniomaxillofac Surg. 2000;28(3):133-9. DOI: http:/doi.org/10.1054/jcms.2000.0134

3. Manson PN. Cranio-orbital fractures. Clin Oral Surg. 1990;2:121-43.

4. Buehler JA, Tannyhill RJ $3^{\text {rd }}$. Complications in the treatment of midfacial fractures. Oral Maxillo fac Surg Clin North Am. 2003;15(2):195-212. 
DOI: http:/doi.org/10.1016/S1042-3699(03) 00 002-5

5. Andrew A. Winkler, Timothy L. Smith, Tanya K. Meyer, The Management of Frontal Sinus Fractures, Chapter 15, page: 149-157, in Kountakis SE, Onerci TM. Eds. Rhinologic and sleep apnoea surgical techniques. New York: Springer; 2007.

6. Ceallaigh PO, Ekanaykaee K, Beirne CJ, Patton DW. Diagnosis and management of common maxillofacial injuries in the emergency department. Part 1: Advanced trauma life support. Emerg Med J. 2006 Oct; 23(10):796-7. DOI: http:/doi.org/10.1136/emj.2006.035931
7. Vadysinghe AN, Senasinghe P, Sivasubramanium M, Jayasooriya P, Premarathna BG, Rathnayake RMISD, Wickramasinghe WMMHP. Unnatural Deaths of the Elderly Population of Sri Lanka: A Descriptive Analysis. Am J Forensic Med Pathol. 2018 Feb 15.

DOI: http://doi.org/10.1097/PAF.000000000000 0383

8. Dazert S1, Mlynski R, Brors D, Sudhoff H, Prescher A, Article in German, Infection transfer between the maxillary sinus and endocranium. HNO. 2004 Jul;52(7):631-4

DOI: http:/doi.org/10.1007/s00106-003-0955-2 